\title{
The burden of illness of osteoporosis in Canada
}

\author{
J.-E. Tarride • R. B. Hopkins • W. D. Leslie • S. Morin • \\ J. D. Adachi $\cdot$ A. Papaioannou $\cdot$ L. Bessette • \\ J. P. Brown • R. Goeree
}

Received: 23 June 2011 / Accepted: 21 December 2011 /Published online: 8 March 2012

(C) The Author(s) 2012. This article is published with open access at Springerlink.com

\begin{abstract}
Summary To update the 1993 burden of illness of osteoporosis in Canada, administrative and community data were used to calculate the 2010 costs of osteoporosis at $\$ 2.3$ billion in Canada or $1.3 \%$ of Canada's healthcare expenditures. Prevention of fractures in high-risk individuals is key to decrease the financial burden of osteoporosis.

Introduction Since the 1996 publication of the burden of osteoporosis in 1993 in Canada, the population has aged and the management of osteoporosis has changed. The study purpose was to estimate the current burden of illness due to osteoporosis in Canadians aged 50 and over.
\end{abstract}

J.-E. Tarride $(\bowtie) \cdot$ R. B. Hopkins $\cdot$ R. Goeree

Programs for Assessment of Technology in Health (PATH)

Research Institute, St Joseph's Healthcare Hamilton,

25 Main Street West, Suite 2000,

Hamilton, ON L8P 1H1, Canada

e-mail: tarride@mcmaster.ca

J.-E. Tarride $\cdot$ R. B. Hopkins $\cdot$ R. Goeree

Department of Clinical Epidemiology and Biostatistics,

McMaster University,

Hamilton, ON, Canada

W. D. Leslie

Department of Medicine, University of Manitoba,

Winnipeg, MB, Canada

S. Morin

Department of Medicine, McGill University,

Montréal, QC, Canada

J. D. Adachi · A. Papaioannou

Department of Medicine, McMaster University,

Hamilton, ON, Canada

L. Bessette · J. P. Brown

Department of Medicine, Laval University,

Quebec City, QC, Canada
Methods Analyses were conducted using five national administrative databases from the Canadian Institute for Health Information for the fiscal-year ending March 312008 (FY 2007/2008). Gaps in national data were supplemented by provincial and community data extrapolated to national levels. Osteoporosis-related fractures were identified using a combination of most responsible diagnosis at discharge and intervention codes. Fractures associated with severe trauma codes were excluded. Costs, expressed in 2010 dollars, were calculated for osteoporosis-related hospitalizations, emergency care, same day surgeries, rehabilitation, continuing care, homecare, long-term care, prescription drugs, physician visits, and productivity losses. Sensitivity analyses were conducted to measure the impact on the results of key assumptions.

Results Osteoporosis-related fractures were responsible for 57,413 acute care admissions and 832,594 hospitalized days in FY 2007/2008. Acute care costs were estimated at $\$ 1.2$ billion. When outpatient care, prescription drugs, and indirect costs were added, the overall yearly cost of osteoporosis was over $\$ 2.3$ billion for the base case analysis and as much as $\$ 3.9$ billion if a proportion of Canadians were assumed to be living in long-term care facilities due to osteoporosis. Conclusions Osteoporosis is a chronic disease that affects a large segment of the adult population and results in a substantial economic burden to the Canadian society.

Keywords Burden of illness - Canada · Fragility fracture · Health economics · Osteoporosis

\section{Introduction}

Osteoporosis Canada recently updated the 2002 clinical practice guidelines for the diagnosis and management of osteoporosis in Canada [1,2]. The new guidelines [1] 
emphasize the need to assess for fracture risk in order to prevent the excess morbidity, mortality, and economic burden associated with osteoporosis and associated fragility fractures. While the direct economic burden of osteoporosis in Canada was estimated at $\$ 1.3$ billion dollars in 1993 (\$1.8 billion in 2010 dollars) [3], no recent study has updated these results despite the fact that many changes have occurred in patient demographics and disease management. Indeed, the Canadian population aged 50 and over has increased from 7.3 million in 1993 to 11.0 million in 2008 [4], and new risk assessment tools and treatment options have been introduced. To have a better understanding of the current economic burden of osteoporosis in Canada, we estimated the 2010 burden of illness of osteoporosis among Canadians aged 50 and over.

\section{Methods}

\section{Overview}

This prevalence-based burden of illness study was conducted using national, provincial, and community data. National data estimates were used if available. Gaps in national data were filled with provincial data extrapolated to the national level based on population demographics (i.e., age and sex). Sensitivity analyses were conducted to assess the impact of key assumptions on the estimates. All costs are presented in 2010 Canadian dollars and both a payer and a societal perspective were taken. When necessary, costs were inflated to 2010 using the Consumer Price Index of Statistics Canada [5].

\section{Data sources}

Five data sets from the Canadian Institute for Health Information (CIHI) were used to gather Canadian data on acute care (Discharge Abstract Database-DAD) [6], emergency visits (National Ambulatory Care Reporting System-NACRS) [7], same day surgery (NACRS for Ontario), rehabilitation services (National Rehabilitation Reporting System-NRS) [8], home care (Home Care Reporting System-HCRS) [9], and continuing care (Continuing Care Reporting System - CCRS) [10]. IMS Health [11] and Brogan Inc. [12] provided data to estimate osteoporosis-related physician and prescription drug costs. Patient and caregiver productivity losses were calculated using data from the Canadian Multicentre Osteoporosis Study (CaMos) [13] and Statistics Canada [14, 15]. In addition to these national data sources, fracture data from the Recognizing Osteoporosis and Its Consequences in Quebec (ROCQ) program [16], from the Resident Assessment Instrument for Home Care (RAI-HC) of Ontario, and from the Manitoba Centre for Health Policy (MHCP) [17] were used to fill gaps or to check results for consistency.
Identification of fractures and attribution to osteoporosis

For the fiscal year April 1, 2007 to March 31, 2008 (FY 2007/2008), fractures in Canadians 50+ were identified in CIHI databases using two definitions: [1] most responsible diagnosis code at discharge of fracture (ICD-10 CA) (see Appendix 1 for a list of codes) or [2] a combination of a secondary code for fracture and an intervention indicative of treatment for a fracture (e.g., fixation, immobilization, reduction, partial excision, repair). The most responsible diagnosis for a patient's stay in hospital is established at discharge and corresponds to the one diagnosis or condition that can be described as being the most responsible for the patient's stay. Fracture records associated with a severe trauma code were excluded from the base case analyses. All low-trauma hip and vertebral fractures were attributed to osteoporosis (i.e., 100\%). The rate of attribution to osteoporosis for wrist, humerus, other, and multiple fractures was derived from Mackey et al. [18] In Mackey et al., the percentages of low-trauma fractures occurring in individuals with low bone mineral density were $74.5 \%$ for men and $90.4 \%$ in women. A $56.0 \%$ attribution rate of osteoporosis for non-hip non-vertebral fractures $(X)$ in men was obtained by solving the following equation with respect to $X$ : number of hip and vertebral fractures in men $\times 100 \%$ osteoporosis attribution rate + number of non-hip non-vertebral fractures in men $\times X \%$ osteoporosis attribution rate)/(total number of fractures in men) $=74.5 \%$ as per Mackey et al.'s results for men. The same exercise was repeated in women to derive an $81.5 \%$ attribution rate of osteoporosis for non-hip nonvertebral fractures.

Estimation of the costs associated with hospitalizations, emergency room visits, and same day surgeries

DAD covers all admissions to acute care hospitals in Canada with the exception of Quebec; Quebec data were therefore extrapolated. Given that Ontario is the only province for which all emergency care visits and same day surgeries are reported in NACRS, the data from Ontario were extrapolated to the national level based on population characteristics. The resource intensity weights (RIW) [19] recorded for each individual were used to assign costs to hospital-stay admissions, emergency room visits, and same day surgeries. RIWs, which are assigned to each patient on discharge, estimate the relative amount of resources needed for a specific admission. Although different RIWs apply to each fracture type, the value of the RIW depends on the Case Mix Group - a Canadian patient classification system assigning similar inpatient cases to a single group - to which they are assigned as well as other factors that affect resource utilization and length of stay (e.g., age, comorbidity levels). Since the RIW does not include the costs related to physician visits (e.g., orthopedic surgeons, 
anesthesiologists, radiologists), diagnostic tests (e.g., X-rays), and procedures (e.g., fixation), these costs were added to RIW costs to determine the total cost of an admission, emergency visit, or same day surgery (i.e., for each patient). The number of physician visits/assessments per admission was derived from the length of stay and costed in function of the fee structure given in Table 1. For example, the value of one physician visit at admission was $\$ 79.20$ while a cost of $\$ 55.45$ was applied to the visit during the second day of hospitalization (Table 1). Table 1 also presents the detailed unit costs associated with the RIW, diagnostics, and procedures.

Estimation of the costs associated with rehabilitation, continuing care, long-term care, and home care

Since NRS and CCRS databases do not report the most responsible diagnosis, DAD was used to identify how many individuals were transferred from acute care to rehabilitation, continuing care, or long-term care facilities. Since the main reason for admission to these facilities prior to the admission was unknown (i.e., not osteoporosis-related), individuals already residing in rehabilitation, continuing care, or long-term care facilities prior to the acute care admission were excluded from the base case analyses in order to be conservative in our estimates. As such, only the excess number of individuals discharged to a particular destination (e.g., number of men discharged to long-term care facilities minus number of men originating from long-term care facilities) was used in the cost calculations. The CIHI-HCRS database on home care in Ontario was used to extrapolate how many Canadians received home care services for osteoporosis-related fractures. Manitoba data were used to estimate the length of stay in long-term care and time receiving home care services following a fracture. All the extrapolations to the national level were adjusted by age and sex.

The costs associated with rehabilitation and continuing care were calculated by multiplying the excess number of individuals transferred from acute care to rehabilitation or continuing care facilities, respectively, by the average NRS and CCRS's RIW inflated for physician visits. Based on Ontario data, daily costs of \$24 and \$148 were applied to home care services and long-term care, respectively (Table 1).

\section{Estimation of physician and prescription drug costs}

The number of physician visits due to osteoporosis was derived from the IMS Health Canada physician survey which is designed to provide information about disease and treatment patterns of physicians in Canada. This sample includes 652 physicians stratified by region and representing all major specialties. Each calendar quarter, the physician reports on all patient contacts for a period of two consecutive days. Physician visit fees were applied to the IMS data according to the Ontario Schedule of Benefits for Physician Services [20]. Costs associated with osteoporosis-related prescription drugs (e.g., alendronate, etidronate, risedronate, zoledronic acid, teriparatide, raloxifene, and calcitonin) were derived from Brogan Inc. Public and private drugs claims collected at pharmacies are adjudicated online and transmitted monthly to IMS Brogan under a data service agreement with the Canadian provincial governments and private drug plans. IMS Brogan covers $100 \%$ and $65 \%$ of all public and private drug claims in Canada, respectively. Private drug claims were extrapolated to national levels. IMS and Brogan data were provided by Amgen Canada.

Estimation of indirect costs

To reflect a societal perspective, time lost from work following an osteoporosis-related fracture and caregiver wage loss were valued. To estimate the productivity losses, the number of days spent in acute and non-acute care (e.g., rehabilitation) was first estimated for individuals aged 50 to 69 using CIHI data. This number was multiplied by the labor force participation rate (i.e., $77 \%$ of individuals aged 50 to 59 and $45 \%$ of individuals aged 60 to 69 [15]) and by the Canadian average daily wage for that age group (\$24.12 per hour $\times 8$ h per day) [14]. Based on CaMos [21] and CIHI data, the value of caregiver wage loss was calculated by multiplying the number of osteoporosis-related admissions by the percentage of patients using caregivers (47.2\%) times the number of days of care (37 days) times the percentage of caregivers being employed (35.8\%) times the average daily wage (\$24.12 per hour $\times 8 \mathrm{~h})$.

\section{Sensitivity analyses}

Several sensitivity analyses were conducted to assess the impact of key assumptions on the burden of illness estimates. First, the assumptions related to the attribution to osteoporosis in women were changed by using Quebec data on fragility fractures among 2,075 women 50 years and older (e.g., $75.7 \%$ between the ages of 50 to 59 years old to $91.8 \%$ in the group over the age of 80 ) [22]. Second, although we identified individuals who were hospitalized with a most responsible diagnosis code of osteoporosis but without a diagnosis of fracture or intervention code, the base case analysis excluded those individuals, as we were uncertain how to attribute the admission. In an additional sensitivity analysis, we included these cases in our cost estimates. Third, in the absence of accurate data on the reasons for admissions to long-term care facilities, the primary analysis ignored the costs associated with those individuals residing on a yearly basis in long-term care facilities due to osteoporosis. Based on an economic model developed for the 
Table 1 Unit costs, data sources, and main costing assumptions

\begin{tabular}{|c|c|c|c|}
\hline Cost component & Item & Unit costs (data source) & Main costing assumptions \\
\hline \multirow{4}{*}{$\begin{array}{l}\text { Acute care (includes acute care } \\
\text { bed admissions, emergency } \\
\text { room visits, day surgeries- } \\
\text { with identical methodology) }\end{array}$} & Cost per RIW & $\$ 5,399.04$ (CIHI) & $\begin{array}{l}\text { - Quebec hospitalizations } \\
\text { extrapolated from all other } \\
\text { Canadian provinces }\end{array}$ \\
\hline & Physician visit fees ${ }^{\mathrm{a}}$ & $\begin{array}{l}\$ 79.20 \text { (admission); } \$ 55.45 \\
\text { (2nd, 3rd, and last day); } \\
\$ 29.20 \text { (other days) (OSBPS) }\end{array}$ & $\begin{array}{l}\text { Ontario data on number } \\
\text { of same day surgeries and } \\
\text { emergency room visits } \\
\text { extrapolated to Canada }\end{array}$ \\
\hline & Diagnostic tests & $\begin{array}{l}\text { Range from } \$ 33 \text { for wrist X-ray } \\
\text { to } \$ 117 \text { for MRI of vertebral } \\
\text { fracture (average of } \$ 75 \text { ) (OSBPS) }\end{array}$ & - Patient-level costing \\
\hline & $\begin{array}{l}\text { Surgeon, surgical assistant, } \\
\text { and anesthesiologist } \\
\text { procedure fees for } \\
\text { assessment, procedure, } \\
\text { and follow-up }\end{array}$ & $\begin{array}{l}\text { Range from } \$ 76 \text { immobilization } \\
\text { of hip to } \$ 2,551 \text { for fixation or } \\
\text { reduction for vertebral fracture } \\
\text { (average } \$ 1,352 \text { ) (OSBPS) }\end{array}$ & \\
\hline \multirow[t]{3}{*}{ Rehabilitation } & Cost per RIW per stay & $\$ 15,449$ (CIHI) & $\begin{array}{l}\text { Based on net transfers } \\
\text { from acute care }\end{array}$ \\
\hline & & & $\begin{array}{l}\text { - Length of stay and costing } \\
\text { based on rehabilitation } \\
\text { database }\end{array}$ \\
\hline & & & - Patient-level costing \\
\hline \multirow[t]{3}{*}{ Continuing care } & Cost per RIW per day & $\$ 420.12$ (CIHI) & $\begin{array}{l}\text { - Based on net transfers } \\
\text { from acute care }\end{array}$ \\
\hline & & & $\begin{array}{l}\text { - Length of stay and costing } \\
\text { based on continuing database }\end{array}$ \\
\hline & & & - Patient-level costing \\
\hline \multirow[t]{2}{*}{ Home care } & Cost per week & $\$ 168.50$ (MDS Inter-rai) & $\begin{array}{l}\text { - Ontario data on number of } \\
\text { recipients extrapolated to } \\
\text { Canada }\end{array}$ \\
\hline & & & $\begin{array}{l}\text { - Length of stay based } \\
\text { on Manitoba data and } \\
\text { unit costs from Ontario }\end{array}$ \\
\hline \multirow[t]{2}{*}{ Long-term care } & Cost per day & $\begin{array}{l}\$ 147.77 \text { (Ontario } \\
\text { provincial budget) }\end{array}$ & $\begin{array}{l}\text { Based on net transfers } \\
\text { from acute care }\end{array}$ \\
\hline & & & $\begin{array}{l}\text { - Length of stay based } \\
\text { on Manitoba data and } \\
\text { unit costs from Ontario }\end{array}$ \\
\hline \multirow[t]{2}{*}{$\begin{array}{l}\text { Outpatient } \\
\text { physician services }\end{array}$} & Physician visit fees & $\begin{array}{l}\text { General practice: consultation } \\
\text { (1 per year) } \$ 56.10 \text {, repeat } \\
\text { consultation } \$ 42.35\end{array}$ & $\begin{array}{l}\text { Assume } 50 \% \text { of visits } \\
\text { are consultation and } 50 \% \\
\text { are repeat consultations }\end{array}$ \\
\hline & & $\begin{array}{l}\text { Internal medicine: consultation } \\
\$ 132.50 \text {, repeat consultation } \$ 82.90\end{array}$ & \\
\hline \multirow[t]{2}{*}{ Drug costs } & $\begin{array}{l}\text { National estimates from } \\
\text { public and private plans }\end{array}$ & $\begin{array}{l}\text { Retail drug price as charged, } \\
\text { plus } \$ 7.00 \text { dispensing fee } \\
\text { (IMS Brogan PharmaStat }(\text { ) }\end{array}$ & $\begin{array}{l}100 \% \text { of public data programs } \\
\text { covered in most provinces } \\
\text { (except PEI and Social } \\
\text { Services in Alberta) }\end{array}$ \\
\hline & & & $\begin{array}{l}\text { Over } 65 \% \text { of all national } \\
\text { privately reimbursed } \\
\text { prescriptions }\end{array}$ \\
\hline Productivity losses & Cost per day & $\begin{array}{l}\$ 24.12 \text { per hour } \times 8 \text { h per } \\
\text { day (Statistics Canada) }\end{array}$ & $\begin{array}{l}\text { - Number of days based } \\
\text { on CAMOS data }\end{array}$ \\
\hline
\end{tabular}

$R I W$ resource intensity weight, $C I H I$ Canadian Institute for Health Information, OSBPS Ontario Schedule of Benefits for Physician Services, $M D S$ Inter-rai minimal data set

${ }^{a}$ For example, fees associated with orthopedic surgeons, anesthesiologists, and radiologists as not included in RIW

IMS Brogan data request: http://www.store.imshealth.com/ 
Ontario Ministry of Health and Long Term Care's Medical Advisory Secretariat [23], it was estimated that $17 \%$ of men and $21 \%$ of women over the age of 65 were residents in long-term care facilities following an osteoporosis-related fracture. Finally, the last sensitivity analysis was conducted assuming that all high and low-trauma fractures were due to osteoporosis. This scenario was based on the evidence generated by Mackey et al. showing that low BMD predicts both high and low-trauma fractures [18] and that antiresorptive treatments prevent high- and low-trauma fractures [24], leading to the recommendation for using all fractures as standard outcomes in osteoporosis trials and observational studies.

\section{Results}

Hospitalizations, same day surgeries, and emergency room visits due to osteoporosis-related fractures

As shown in Table 2, CIHI data for all Canadian provinces except Quebec indicated that 44,707 hospitalizations were attributable to osteoporosis-related fractures in FY 2007/ 2008. The number of osteoporosis-related fractures in Quebec was estimated at 12,706 for a total of 57,413 hospitalizations in Canada. These hospitalizations resulted in 832,594 hospitalized days. The mean length of stay was 14.5 days [median $(\mathrm{Q} 1, \mathrm{Q} 3)=7(1,0.15)$ days]. Fractures in women accounted for approximately $70 \%$ of all hospital admissions (men-16,855; women-40,550) and hospitalized days (men-228,231; women -604,363). Among women, hip fractures accounted for half of the hospitalized days (316,607 out of 604,363). Over $70 \%$ of all fractures occurred in individuals older than 70 years with the highest number of hospitalizations observed in the $81-90$ years age group $(21,033$ of 57,413$)$. In addition, osteoporosis-related fractures resulted in 112,740 emergency room visits and 3,433 same day surgeries. Eighty percent of all same day surgeries were due to wrist fractures while wrist
(30\%), hip (23\%), and other fracture sites (30\%) accounted for more than $80 \%$ of all osteoporosis-related fracture visits to the ER (Fig. 1).

Costs associated with hospitalizations, same day surgeries, and emergency room visits

The costs associated with osteoporosis-related fracture hospitalizations, same day surgery, and emergency visits in FY $2007 / 2008$ were estimated at $\$ 1.2$ billion, of which $85 \%$ was due to hospitalizations (Table 3). Fractures in women and of the hip accounted for $71 \%$ and $53 \%$ of the acute care costs, respectively (Table 3). Hospitalizations following fractures at multiple sites and hip fractures were the most costly at approximately $\$ 23,404$ and $\$ 20,163$ per hospitalization, respectively. The average cost of a hospitalization for wrist fracture was the lowest at $\$ 8,848$ while humerus, vertebral, or other sites-related hospitalizations cost approximately $\$ 13,000$. Hospitalization costs increased with age (e.g., from $\$ 11,434$ in women aged $50-59$ to $\$ 19,456$ in women aged 80-89). The increased costs were driven by longer lengths of stay (e.g., an average of 7.8 days for individuals aged 50 59 versus 17.4 days for $80-89$ years old). No major differences between fracture sites or age groups were observed in terms of costs associated with same day surgery $(\$ 3,166$ to $\$ 4,238$ ) or emergency room visits (e.g., $\$ 816$ to $\$ 1,913$ ).

Costs associated with rehabilitation, continuing care, long-term care, and home care

Figure 2 presents the information used to calculate the net number of patients discharged to rehabilitation, continuing care, and chronic care (i.e., discharge location-entrance). For example, although 5,714 were discharged to rehabilitation facilities, 133 patients ( 78 hip fractures) were admitted from a rehabilitation facility to acute care for a net transfer of 5,581 individuals. While $15 \%$ of all hip fractures were discharged to rehabilitation facilities $(N=4,284)$, hip fracture accounted for

Table 2 Canadian hospitalizations and hospitalized days for osteoporosis-related fractures by gender and type of fracture (fiscal year 2007/2008)

\begin{tabular}{|c|c|c|c|c|c|c|c|c|}
\hline \multirow[t]{2}{*}{$\begin{array}{l}\text { Fracture } \\
\text { type }\end{array}$} & \multicolumn{3}{|c|}{$\begin{array}{l}\text { Number of hospitalizations: } \\
\text { all Canada except Quebec }\end{array}$} & \multicolumn{3}{|c|}{$\begin{array}{l}\text { Number of hospitalizations: } \\
\text { Quebec (extrapolated) }\end{array}$} & \multirow{2}{*}{$\begin{array}{l}\text { Number of hospitalizations: } \\
\text { Canada } \\
\text { Total }\end{array}$} & \multirow{2}{*}{$\begin{array}{l}\text { Number of hospitalized } \\
\text { days: Canada } \\
\text { Total }\end{array}$} \\
\hline & Women & Men & Total & Women & Men & Total & & \\
\hline Hip & 15,519 & 6,165 & 21,684 & 5,156 & 2,027 & 7,183 & 28,867 & 448,776 \\
\hline Humerus & 1,623 & 4,54 & 2,077 & 397 & 111 & 508 & 2,585 & 30,141 \\
\hline Vertebral & 1,077 & 6,45 & 1,722 & 360 & 215 & 575 & 2,297 & 34,490 \\
\hline Wrist & 2,983 & 9,37 & 3,920 & 714 & 224 & 938 & 4,858 & 24,132 \\
\hline Multiple site & 3,325 & 1,579 & 4,904 & 762 & 362 & 1,124 & 6,028 & 124,000 \\
\hline Other site & 7,034 & 3,366 & 10,400 & 1,608 & 770 & 2,378 & 12,778 & 171,055 \\
\hline Total & 31,561 & 13,146 & 44,707 & 8,997 & 3,709 & 12,709 & 57,413 & 832,594 \\
\hline
\end{tabular}




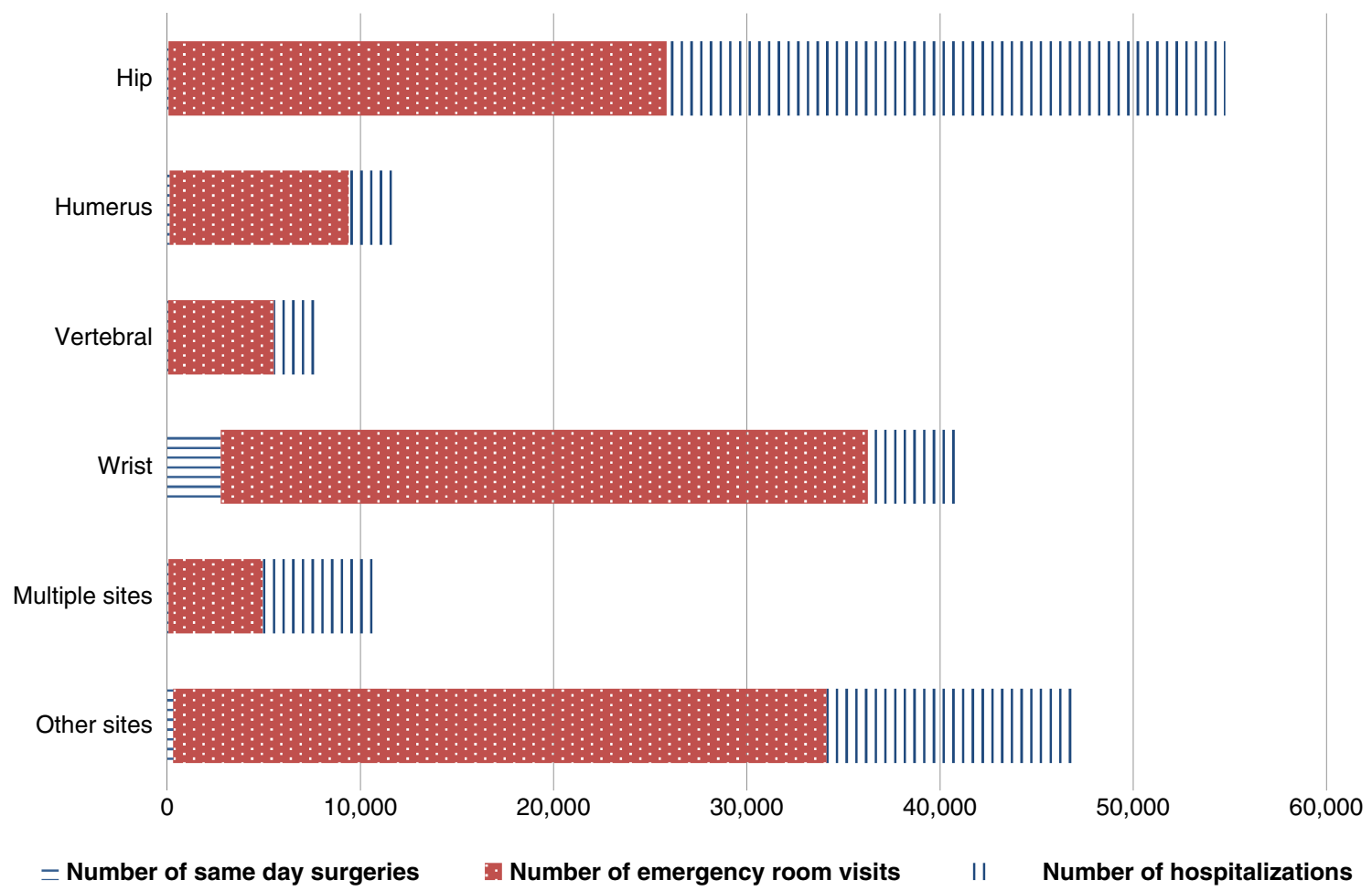

Fig. 1 Number of same day surgeries, emergency room visits, and hospitalizations by type of osteoporosis-related fracture in Canada in fiscal year 2007/2008 (independent of discharge destination)

$75 \%$ of all discharges to rehabilitation facilities $(N=4,284$ out of 5,714$)$. With an average cost per day of $\$ 736$ and a total of 131,944 days spent in rehabilitation services, the cost associated with osteoporosis-related rehabilitation facilities was estimated to be over $\$ 97$ million.

Similar calculations were used to determine the net number of individuals discharged to continuing care $(n=2,391)$. Each individual spent on average 91 days in continuing care for a total of $\$ 113$ million. Although $15 \%$ of hospitalized individuals were discharged to long-term care $(n=8,707)$ for an average duration of 194 days, $12 \%$ of those $(n=7,152)$ were already living in long-term care before being hospitalized. The cost associated with the net transfers to long-term care facilities was estimated at \$28 million. Based on home care data from Ontario, we estimated that 50,398 Canadians received home care services following osteoporosis-related fractures at a cost of $\$ 245$ million, of which $41 \%$ was due to hip fracture.

Physician and prescription drug costs

According to IMS data, there were more than 2.3 million osteoporosis-related physician visits in 2008 for a total of $\$ 143$ million. Visits to general practitioners accounted for $81 \%$ of all visits. Brogan estimates indicated that $\$ 391$

Table 3 Acute care costs (2010 Canadian dollars)

\begin{tabular}{llllll}
\hline Fracture type & Emergency care & Acute care admissions & Same day surgery & Total acute care costs & Percent of total costs \\
\hline Hip & $\$ 40,493,177$ & $\$ 582,058,662$ & $\$ 288,169$ & $\$ 622,840,008$ & $53 \%$ \\
Humerus & $\$ 11,681,974$ & $\$ 32,324,504$ & $\$ 451,514$ & $\$ 44,457,992$ & $4 \%$ \\
Vertebral & $\$ 5,186,182$ & $\$ 31,720,622$ & $\$ 237,393$ & $\$ 37,144,197$ & $3 \%$ \\
Wrist & $\$ 55,420,934$ & $\$ 43,028,096$ & $\$ 9,497,406$ & $\$ 107,946,436$ & $9 \%$ \\
Multiple sites & $\$ 9,322,424$ & $\$ 141,035,749$ & $\$ 321,292$ & $\$ 150,679,465$ & $13 \%$ \\
Other sites & $\$ 38,803,610$ & $\$ 178,163,216$ & $\$ 1,239,783$ & $\$ 218,206,609$ & $18 \%$ \\
Total & $\$ 160,908,302$ & $\$ 1,008,330,849$ & $\$ 12,035,556$ & $\$ 1,181,274,707$ & $100 \%$ \\
Percent of total costs & $14 \%$ & $85 \%$ & $1 \%$ & $100 \%$ & \\
Percent of total costs & $72 \%$ & $71 \%$ & $76 \%$ & $71 \%$ & \\
\multicolumn{1}{l}{ attributed to women } & & & & & \\
\hline
\end{tabular}


Fig. 2 Entrance and discharge institutions following hospitalization for osteoporosis-related fracture $(N=57,433)$

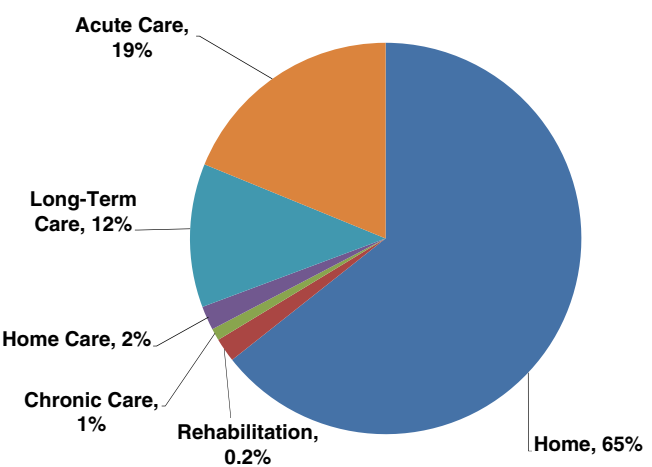

ENTRANCE

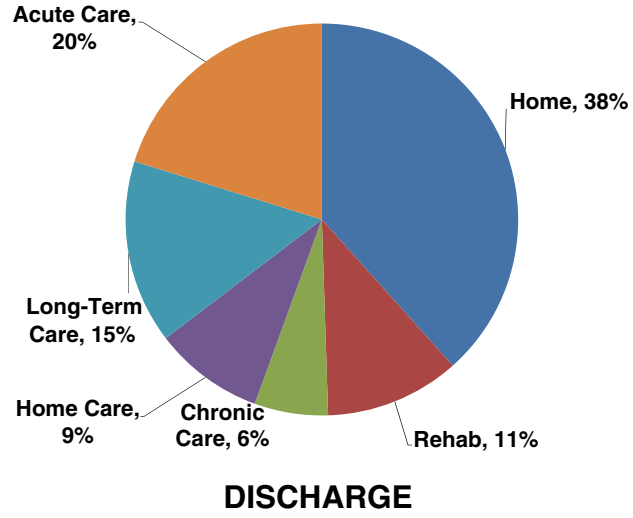

million were spent in 2008 in osteoporosis-related medications. More than $70 \%$ of this cost was incurred by public plans (\$278 million).

\section{Indirect costs}

The number of days missed from work due to osteoporosisrelated fractures was estimated at 3,123,298 days $(12,013$ full-time employment years) for individuals aged 50 to 69 years. Days spent in hospital or receiving home care services accounted for more than $90 \%$ of all days not available from work. When labor force participation rates were applied to this data, the costs associated with time loss from work was estimated at $\$ 46$ million. Caregiver wage losses were calculated at $\$ 69$ million, for a total of $\$ 115$ million in indirect costs.

Burden of osteoporosis: base case and sensitivity analyses

The base case estimates of the cost of osteoporosis in Canada in FY 2007/2008 were \$2.3 billion (Table 4). Changing the rate of attribution to osteoporosis of fractures in women by using Quebec data rather than US data decreased the cost by $2 \%$. Adding the cost associated with 2,096 cases with a most responsible diagnosis of osteoporosis alone increased the cost by $2 \%$. In the sensitivity analysis assuming that $17 \%$ and $21 \%$ of men and women, respectively, were living in long-term care facilities due to osteoporosis, the total estimates increased to $\$ 3.9$ billion (Table 4). In another sensitivity analysis assuming that all high and low-trauma fractures were due to osteoporosis, the base case estimates increased by $9 \%$ to $\$ 2.5$ billion. Taken together, these results indicated that the upper bound of the burden of osteoporosis in Canada could be $\$ 4.1$ billion when it was assumed that all trauma fractures were osteoporotic and that $17 \%$ of men and $21 \%$ of women over the age of 65 were admitted to long-term facilities due to osteoporosis.

\section{Discussion}

In addition to the increased morbidity and mortality associated with fractures $[25,26]$, these results show that osteoporosis among Canadians aged 50 years and older is associated with a substantial economic cost accounting in 2008 for $\$ 2.3$ billion or $1.3 \%$ of Canadian healthcare budget [27]. Specifically, our base case results indicated that osteoporosis was responsible for more than 57,413 hospitalizations and 832,594 hospitalized days in FY 2007/2008. This is more than the number of hospitalizations due to stroke $(29,874$ in FY 2007/2008) or heart attack $(49,220$ in FY 2007/2008) in Canada [28]. The acute care cost of managing these fractures was over $\$ 1.2$ billion, or $50 \%$ of the total costs.

In contrast to the previous 1993 Canadian burden of illness study [4] which assumed that there were approximately 18,000 Canadians aged 75 years or over in long-term care facilities due to osteoporosis, our base case estimates did not include these individuals as the main reason of admission to long-term facilities could not be determined (e.g., hip fracture versus dementia with hip fracture as the sentinel event), making direct comparisons between the two studies difficult. However, when we included these individuals in a sensitivity analysis, the burden of illness estimate increased to $\$ 3.9$ billion, which was approximately the double of the 1993 estimate expressed in 2010 dollars (\$1.8 billion). Our cost estimates of the acute care treatment of osteoporosisrelated fractures were also twice that of the 1993 estimates expressed in 2010 dollars ( $\$ 1.2$ billion versus $\$ 0.6$ billion, respectively). Several reasons can explain these differences and caution should be exercised when comparing the 1993 and 2010 burden of illness estimates. First, the Canadian population aged 50 years and over has increased by $50 \%$ from 1993 to 2008, which may explain the increase in the number of hospitalized hip fractures between $1993(N=21,302)$ and $2008(N=28,867)$. Although the number of hospitalizations due to wrist fractures in Canada also increased from 2,149 to 4,858 during the same time period, the number of vertebral 
Table 4 Burden of osteoporosis: base case and sensitivity analyses (2010 Canadian dollars)

\begin{tabular}{|c|c|c|c|c|c|}
\hline $\begin{array}{l}\text { Cost } \\
\text { component }\end{array}$ & $\begin{array}{l}\text { Base case } \\
\text { analysis }\end{array}$ & $\begin{array}{l}\text { Change attribution rates } \\
\text { of osteoporosis using } \\
\text { ROCQ data instead } \\
\text { of MacKey et al. }\end{array}$ & $\begin{array}{l}\text { Add costs attributed } \\
\text { to hospitalizations } \\
\text { due to osteoporosis } \\
\text { only }(N=2,096)\end{array}$ & $\begin{array}{l}\text { Assumes that a proportion } \\
\text { of long-term care residents } \\
\text { were admitted due to } \\
\text { osteoporosis-related fractures }\end{array}$ & $\begin{array}{l}\text { Assumes that all } \\
\text { high and low- } \\
\text { trauma fractures } \\
\text { are osteoporotic }\end{array}$ \\
\hline $\begin{array}{l}\text { Acute care costs } \\
\text { (hospitalization, } \\
\text { same day surgeries, } \\
\text { and emergency } \\
\text { room visits) }\end{array}$ & $\$ 1,181,274,707$ & $\$ 1,134,803,061$ & $\$ 1,219,450,008$ & Unchanged & $\$ 1,318,689,391$ \\
\hline $\begin{array}{l}\text { Rehabilitation } \\
\text { costs }\end{array}$ & $\$ 97,169,606$ & $\$ 95,280,270$ & $\$ 103,457,541$ & Unchanged & $\$ 120,170,851$ \\
\hline $\begin{array}{l}\text { Continuing } \\
\text { care costs }\end{array}$ & $\$ 112,720,625$ & $\$ 110,024,143$ & $\$ 119,837,738$ & Unchanged & $\$ 140,969,693$ \\
\hline Long-term care & $\$ 28,275,046$ & $\$ 26,487,393$ & Unchanged & $\$ 1,641,017,974$ & $\$ 46,532,134$ \\
\hline $\begin{array}{l}\text { Home care } \\
\text { services }\end{array}$ & $\$ 244,565,735$ & Unchanged & Unchanged & Unchanged & Unchanged \\
\hline Physician costs & $\$ 142,589,880$ & Unchanged & Unchanged & Unchanged & Unchanged \\
\hline $\begin{array}{l}\text { Prescribed } \\
\text { drug costs }\end{array}$ & $\$ 390,854,843$ & Unchanged & Unchanged & Unchanged & Unchanged \\
\hline Indirect costs & $\$ 115,311,966$ & $\$ 115,045,033$ & Unchanged & Unchanged & $\$ 117,076,070$ \\
\hline Total cost & $\$ 2,312,762,408$ & $\$ 2,263,759,530$ & $\$ 2,364,342,757$ & $\$ 3,925,505,337$ & $\$ 2,519,684,494$ \\
\hline
\end{tabular}

ROCQ Recognizing Osteoporosis and its Consequences

fractures decreased from 5,764 to 2,297. The use of a broader diagnostic code in the previous study to identify vertebral fractures may explain this difference. For example, the 1993 estimate of the number of vertebral fractures included fractures of the sacrum and coccyx, which were not considered in our study. Second, in addition to hip, wrist, and vertebral fractures, the costs associated with fractures of the humerus, multiple, and other sites were also included in our study while these fractures were not considered in determining the 1993 estimates. As such, it is more appropriate to compare the 1993 acute care costs (i.e., $\$ 0.6$ billion in 2010 dollars) to the 2010 acute care costs associated with hip, wrist, and vertebral fractures only (i.e., $\$ 0.8$ billion). Considering that the acute care costs associated with the other types of osteoporosis-related fractures accounted for 0.4 billion in our study, the 1993 acute care costs may have been an underestimation of the burden of osteoporosis. Interestingly enough, the 1993 average inpatient cost per hip fracture in 2010 dollars $(\$ 457$ million for 21,233 hip fractures or an average of approximately $\$ 21,500$ per hip fracture) was similar to our figure ( $\$ 622$ million for 28,267 hip fractures or approximately $\$ 21,600$ per hip fracture). It was not possible to compare the average hospitalization/acute care cost per wrist or vertebral fracture between the two studies as the 1993 estimates included the outpatient costs associated with the management of wrist and vertebral fractures. Third, although the two studies were primarily based on CIHI data to estimate the acute care costs attributable to osteoporosis, different methods and data sources were used when estimating non-acute care costs. For example, we included the costs associated with rehabilitation and home care services which were not taken into consideration in the 1993 estimates. However, our long-term care cost estimates were double that of the 1993 study ( $\$ 1.6$ billion versus $\$ 0.8$ billion, respectively) when we assumed that a proportion of individuals were living in long-term care due to osteoporosis $(N=30,425$ compared to $N=19,900$ in the 1993 study). This translated into an average of approximately $\$ 54,000$ per long-term care resident in our study versus $\$ 38,000$ in the previous study (in 2010 Canadian dollars). Another difference between the two studies relates to the higher costs of prescription drugs in our study (i.e., \$391 million versus \$20 million in 1993) which is consistent with the introduction of new treatment options for osteoporosis. Finally, our estimate of the physician costs attributable to osteoporosis was almost ten times higher than the 1993 estimates (i.e., $\$ 143$ million versus $\$ 18$ million in 1993). Difference in methods (e.g., expert opinion in the 1993 study versus IMS data in the 2010 study) may explain this difference.

Although it is difficult to directly compare our Canadian estimates with burden of illness studies conducted outside of Canada [29-37] due to differences in demographic variables (e.g., age, sex), methods (e.g., identification of osteoporosisrelated fractures; cost categories included in estimates), or health care delivery systems (e.g., long-term care), our Canadian estimates were consistent with a recent US study which used a representative sample of Medicare to estimate the annual medical costs of osteoporosis in the elderly at \$22 billion in 2008 [29]. Although the majority of burden of illness studies only reported the costs associated with osteoporosisrelated hospitalizations [32, 34-36], non-acute care accounted for almost $50 \%$ of our base case direct cost estimates, which 
was higher than estimates reported in the US (38\%) [37], Germany (33\%) [30], and New Zealand (33\%) [31]. Differences in the cost categories included in the non-acute care calculations may explain these variations (e.g., home care and long-term care). From a societal perspective, our results indicated that indirect costs accounted for $5 \%$ of the total costs, which was lower than an estimate from Germany (i.e., 15\%) [30]. While we calculated indirect costs in terms of productivity losses and caregiver time loss due to treatment and rehabilitation of osteoporotic fractures, Brecht et al. [30] incorporated the unfitness for work, early retirement, and premature mortality in their calculations. As very few burden of illness studies have taken a societal perspective in their approach, determining the indirect costs associated with osteoporosis is an important area of future research.

Despite its strengths (e.g., patient-level data for many administrative datasets; national and provincial data), several limitations were associated with this study. First, the burden of osteoporosis in Quebec was estimated rather than derived from Quebec administrative data. However, our projected estimates of the number of osteoporosis-related fractures and associated inpatient costs in women were close to the estimates derived from the Recognizing Osteoporosis and its Consequences (ROCQ) Quebec cohort [22, 38]. Like other administrative data, there is always a risk of misclassification when reporting diagnostic information. For this reason, we excluded for the base case results those osteoporosis cases without a fracture or relevant intervention codes. Although we used the most responsible diagnosis at discharge to identify the population of study, some of the days spent in hospitals may be related to other conditions. In the absence of national data, we extrapolated provincial data to national levels by adjusting for differences in age and gender characteristics. However, we were not able to adjust for fracture types which may be different between provinces. However, little differences in hip fracture rates were observed between Canadian provinces [39]. We also used provincial unit costs assuming that the data may be representative of other Canadian provinces, which may not be true. However, we found very little variation in the average value of the RIWs between Canadian provinces (less than 5\%). Similarly in the absence of data, the costs associated with primary and community care of fractures were not captured in our analyses (e.g., vertebral fractures most commonly treated in outpatient settings), which may result in an underestimation of the true cost of osteoporosis in Canada. In addition, the costs of therapy may have been underestimated as calcium and vitamin D supplementation costs were not included in our estimates or the costs associated with premature mortality. In the absence of data, we also determined the rate of attribution to osteoporosis for non-hip non-vertebral fractures to match Mackey's estimates, which may have introduced some bias in our calculations. However, the results changed little when Quebec data were used for the attribution rate of osteoporosis in women [22]. Finally we excluded fractures at sites that are not typically related to osteoporosis, such as fractures of the heel, toe, hand, finger, face, or skull.

In conclusion, the burden of osteoporosis in FY 2007/2008 was estimated to range from $\$ 2.3$ billion to $\$ 4.1$ billion. Since the prevalence of osteoporosis increases with age, the burden of osteoporosis is likely to increase over the next decade. As such, prevention of osteoporotic fractures among patients at high risk of fractures is key to decreasing the human and economic burden of osteoporosis. Future research should continue to provide detailed information on the burden of osteoporosis by gender, age group, and fracture type that could be used for resource allocation and prioritization.

Acknowledgment Study funded by an unrestricted grant from Amgen Canada. The authors acknowledge the Manitoba Centre for Health Policy for use of data contained in the Population Health Research Data Repository (HIPC project \#2009/2010-09). The results and conclusions are those of the authors and no official endorsement by the Manitoba Centre for Health Policy, Manitoba Health, or other data providers is intended or should be inferred.

\section{Conflicts of interest None.}

Open Access This article is distributed under the terms of the Creative Commons Attribution License which permits any use, distribution, and reproduction in any medium, provided the original author(s) and the source are credited.

\section{Appendix 1}

Table 5 List of ICD-10 CA codes by type of fracture

\begin{tabular}{ll}
\hline Fracture type & $\begin{array}{l}\text { ICD 10 codes relating to } \\
\text { fracture type }\end{array}$ \\
\hline Hip & $\mathrm{S} 72.0, \mathrm{~S} 72.1, \mathrm{~S} 72.2$ \\
Humerus & $\mathrm{S} 42.2$ \\
Vertebral & $\mathrm{S} 22.0, \mathrm{~S} 22.1, \mathrm{~S} 32.0$ \\
Wrist & $\mathrm{S} 52$ with CCI codes \\
Other sites: & \\
- Femur & $\mathrm{S} 72.3, \mathrm{~S} 72.4, \mathrm{~S} 72.7, \mathrm{~S} 72.8, \mathrm{~S} 72.9$ \\
- Lower leg (tibia, fibula, & $\mathrm{S} 82.0-\mathrm{S} 82.9, \mathrm{~S} 92$ \\
ankle, knee, foot) & \\
- Lower arm (radius, ulna) & $\mathrm{S} 52$ unless wrist above \\
- Other site (rib, shoulder, arm) & $\mathrm{S} 22.3, \mathrm{~S} 42.0, \mathrm{~S} 42.7, \mathrm{~S} 42.8, \mathrm{~S} 42.9$ \\
- Other fractures including: & $\mathrm{S} 22.2, \mathrm{~S} 22.4, \mathrm{~S} 22.8, \mathrm{~S} 22.9$ \\
- ribs/sternum, clavicle, & $\mathrm{S} 32.1, \mathrm{~S} 32.3, \mathrm{~S} 32.4, \mathrm{~S} 32.5$, \\
pelvis, patella, & $\mathrm{S} 32.7, \mathrm{~S} 32.8$ \\
- tibia/fibula, ankle & $\mathrm{S} 42.0-42.9$ except 42.2, S42.7, \\
& $\mathrm{S} 42.8, \mathrm{~S} 42.9$ \\
& $\mathrm{~S} 72.0-72.9$ except when \\
& "hip/femur" from above \\
Multiple fractures & T02.1-T02.9 \\
& $($ or more than 1 of above $)$
\end{tabular}




\section{References}

1. Papaioannou A, Morin S, Cheung AM, Atkinson S, Brown JP, Feldman S, Hanley DA, Hodsman A, Jamal SA, Kaiser SM et al (2010) 2010 clinical practice guidelines for the diagnosis and management of osteoporosis in Canada: summary. CMAJ 182 (17): 1864-1873

2. Brown JP, Josse RG (2002) 2002 clinical practice guidelines for the diagnosis and management of osteoporosis in Canada. CMAJ 167(10 Suppl):S1-S34

3. Statistics Canada (2010) Estimates of population, by age group and sex for July 1, Canada, provinces and territories, annual. Table 051-0001

4. Goeree R, O'Brien B, Pettitt D, Cuddy L, Ferraz M, Adachi JD (1996) An assessment of the burden of illness due to osteoporosis in Canada. J Soc Obstet Gynaecol Can 18(Suppl July):15-24

5. Statistics Canada (2011) Consumer Price Index (CPI) Statistics. Table 176-000

6. Canadian Institute for Health Information (2006) Discharge Abstract Database (DAD) Abstracting Manual, 2007-2008 Edition (Ottawa: CIHI, 2006)

7. Canadian Institute for Health Information (2010) National Ambulatory Care Reporting System (NACRS), Database Background and General Data Limitations Documentation,, 2007-2008 (Ottawa, Ont.: CIHI, 2008)

8. Canadian Institute for Health Information (2010) National Rehabilitation Reporting System (NRS) Data Quality Documentation 2007-2008 (Ottawa, Ont.: CIHI, 2009)

9. Canadian Institute for Health Information (2010) Home Care Reporting System

10. Canadian Institute for Health Information (2010) Continuing Care Reporting System (CCRS) Specifications Manual, 2009 (Ottawa, Ont.: CIHI, 2008)

11. Intercontinental Marketing Services (IMS) Health Canada (2010)

12. IMS Brogan (2010) Brogan PharmaStat ${ }^{\circledR}$ Database. Pharmaceutical Market Data

13. Kreiger N, Joseph L, Mackenzie T, Poliquin S, Brown J, Prior J, Rittmaster R, Tenenhouse A (1999) The Canadian Multicentre Osteoporosis Study (CaMos): background, rationale, methods. Can J Aging 18(3):376-387

14. Statistics Canada (2010) Labour force survey estimates (LFS), wages of employees by type of work, National Occupational Classification for Statistics (NOC-S), sex and age group

15. Statistics Canada (2010) Labour force survey estimates (LFS), by sex and detailed age group, annual

16. Bessette L, Ste-Marie LG, Jean S, Davison KS, Beaulieu M, Baranci M, Bessant J, Brown JP (2008) Recognizing osteoporosis and its consequences in Quebec (ROCQ): background, rationale, and methods of an anti-fracture patient health-management programme. Contemp Clin Trials 29(2):194-210

17. Manitoba Centre for Health Policy. 2010 Available from http:// umanitoba.ca/faculties/medicine/units/community health sciences/ departmental units/mchp/resources/repository/index.html

18. Mackey DC, Lui LY, Cawthon PM, Bauer DC, Nevitt MC, Cauley JA, Hillier TA, Lewis CE, Barrett-Connor E, Cummings SR (2007) High-trauma fractures and low bone mineral density in older women and men. JAMA 298(20):2381-2388

19. Canadian Institute for Health Information (2010) Canadian MIS Database - Hospital Financial Performance Indicators, 1999-2000 to 2008-2009

20. Ontario Ministry of Health and Long Term Care (2010) Schedule of Benefits for Physician Services under the Health Insurance Act

21. Kaffashian S, Raina P, Oremus M, Pickard L, Adachi J, Papadimitropoulos E, Papaioannou A (2011) The burden of osteoporotic fractures beyond acute care: the Canadian Multicentre Osteoporosis Study (CaMos). Age Ageing 40(5):602607

22. Bessette L, Ste-Marie LG, Jean S, Davison KS, Beaulieu M, Baranci M, Bessant J, Brown JP (2008) The care gap in diagnosis and treatment of women with a fragility fracture. Osteoporos Int 19 (1):79-86

23. Medical Advisory Secretariat (2008) The Falls/Fractures Economic Model in Ontario Residents aged 65 Years and Over (FEMOR). Ont Health Technol Assess Ser 8(6)

24. Mackey DC, Black DM, Bauer DC, McCloskey EV, Eastell R, Mesenbrink P, Thompson JR, Cummings SR (2011) Effects of antiresorptive treatment on nonvertebral fracture outcomes. J Bone Miner Res 26(10):2411-2418

25. Papaioannou A, Kennedy CC, Ioannidis G, Sawka A, Hopman WM, Pickard L, Brown JP, Josse RG, Kaiser S, Anastassiades T et al (2009) The impact of incident fractures on health-related quality of life: 5 years of data from the Canadian Multicentre Osteoporosis Study. Osteoporos Int 20(5):703-714

26. Ioannidis G, Papaioannou A, Hopman WM, Akhtar-Danesh N, Anastassiades T, Pickard L, Kennedy CC, Prior JC, Olszynski WP, Davison KS et al (2009) Relation between fractures and mortality: results from the Canadian Multicentre Osteoporosis Study. CMAJ 181(5):265-271

27. Canadian Institute for Health Information (2010) National Health Expenditure Trends, 1975 to 2010 (Ottawa, Ont.: CIHI, 2010)

28. Canadian Institute for Health Information (2009) Health Indicators 2009 (Ottawa, Ont.: CIHI, 2009)

29. Blume SW, Curtis JR (2010) Medical costs of osteoporosis in the elderly Medicare population. Osteoporos Int Dec 17

30. Brecht JG, Schadlich PK (2000) Burden of illness imposed by osteoporosis in Germany. HEPAC 1:26-32

31. Brown P, McNeill R, Leung W, Radwan E, Willingale J (2011) Current and future economic burden of osteoporosis in New Zealand. Appl Health Econ Health Policy 9(2):111-123

32. Clark P, Carlos F, Barrera C, Guzman J, Maetzel A, Lavielle P, Ramirez E, Robinson V, Rodriguez-Cabrera R, Tamayo J et al (2008) Direct costs of osteoporosis and hip fracture: an analysis for the Mexican healthcare system. Osteoporos Int 19(3):269 276

33. Haussler B, Gothe H, Gol D, Glaeske G, Pientka L, Felsenberg D (2007) Epidemiology, treatment and costs of osteoporosis in Germany-the BoneEVA Study. Osteoporos Int 18(1):77-84

34. Johnell O, Kanis JA, Jonsson B, Oden A, Johansson H, De Laet C (2005) The burden of hospitalised fractures in Sweden. Osteoporos Int 16(2):222-228

35. Lippuner K, Golder M, Greiner R (2005) Epidemiology and direct medical costs of osteoporotic fractures in men and women in Switzerland. Osteoporos Int 16(Suppl 2):S8-S17

36. Maravic M, Le BC, Landais P, Fardellone P (2005) Incidence and cost of osteoporotic fractures in France during 2001. A methodological approach by the national hospital database. Osteoporos Int 16(12):1475-1480

37. Ray NF, Chan JK, Thamer M, Melton LJI (1997) Medical expenditures for the treatment of osteoporotic fractures in the United States in 1995: report from the National Osteoporosis Foundation. J Bone Miner Res 12(1):24-35

38. Bessette L, Jean S, Lapointe-Garant MP, Belzile EL, Davison KS, Ste-Marie LG, Brown JP (2011) Direct medical costs attributable to peripheral fractures in Canadian post-menopausal women. Osteoporos Int Sep 17

39. Leslie W, O'Donnell S, Lagace C, Walsh P, Bancej C, Jean S, Siminoski K, Kaiser S, Kendler D, Jaglal S et al (2010) Population-based Canadian hip fracture rates with international comparisons. Osteoporos Int 21(8):1317-1322 